\section{DOENÇA DE NEWCASTLE. I. ESTUDO EXPERIMENTAL DA RESPOSTA IMUNE ÀS ESTIRPES VACINAIS $B_{1}$ E LA SOTA}

\author{
ANTONIO CARLOS PAULILLO \\ Professor Assistente \\ Faculdade de Ciências Agrárias e Veterinárias \\ de Jaboticabal \\ ARAMIS AUGUSTO PINTO \\ Professor Livre-Docente \\ Instituto de Ciências Biomédicas da USP \\ JOJI ARIKI \\ Professor Livre-Docente \\ Faculdade de Ciências Agrárias e Veterinárias \\ de Jaboticabal \\ ANGELO BERCHIERI JUNIOR \\ Auxiliar de Ensino \\ Faculdade de Ciências Agrárias e Veterinárias \\ de Jaboticabal
}

PAULILLO, A.C.; PINTO, A.A.; ARIKI, J.; BERCHIERI JUNIOR, A. Doença de Newcastle. I. Estudo experimental da resposta imune às estirpes vacinais $B_{1}$ e La Sota. Rev.Fac.Med.vet.Zootec.Univ.S.Paulo, 19(1): 39-43, 1982.

RESUMO: Foram utilizados pintos de corte de linhagem comercial, procedentes de matrizes imunizadas, para o estudo de vacinas lentogênicas preparadas com as estirpes $\mathrm{B}_{1}$ e La Sota, do vírus da doença de Newcastle. As estirpes vacinais $B_{1}$ e La Sota, estatisticamente ao nível de $1 \%$ de probabilidade, foram igualmente eficientes no teste de proteção ao desafio, realizado com $10^{7} .2 \% 0,1 \mathrm{mI}$ EID 50 de uma amostra velogênica viscerotrópica de campo administrada pela via ocular. O título de anticorpos inibidores da hemaglutinação (HI) aumentou até o 210 . dia após a vacinação, sendo significativamente maiores para a estirpe La Sota, ao nível de $5 \%$ de probabilidade.

UNITERMOS: Docnça de Newcastle*; Hemoaglutinação*;Vacinas, pintos de corte*

\section{INTRODUÇÃo}

A doença de Newcastle é apontada, sem nenhuma dúvida, como o problema sanitário mais importante do plantel avícola brasileiro, em virtude dos elevados prejuizos que ocasiona.

Nos últimos anos, constatou-se a manifestação da mais patogênica estirpe do vírus da doença de Newcastle, a amostra "Essex 70", caracterizada pela sua elevada virulência e contágio, embora de uma composição antigênica idêntica às formas clássicas, consoante informes de ALLAN e cols $^{1}$ (1973) e de HANSON 7 (1974).

No Brasil, os esforços para o controle dessa enfermidade estశo orientados para a imunização ativa, mediante va. cinas vivas de caráter lentogênico, sendo empregadas exclusivamente as estirpes $B_{1}$ e La Sota.

As vantagens que as vacinas de estirpe La Sota oferecem em relação às de $B_{1}$ foram estudadas por WINTERFIELD e cols 17 (1957), TAVASSOLI'15 (1971), LANDGRAF e VIELITZ10 (1972) e BUTTERFIELD e cols 4 (1973).

$\mathrm{O}$ advento da forma mais virulenta do vírus da doença de Newcastle na última década, conhecida como Newcastle viscerotrópica, enfatiza a realização de um estudo com o intuito de verificar as principais propriedades imunogênicas para cada tipo de vacina em uso na atualidade, motivo da presente investigação.

\section{MATERIAIS E MÉTODOS}

\section{Instalações e Equipamentos}

O experimento foi conduzido no Aviário Experimental da Faculdade de Ciências Agrárias e Veterinárias "campus" de Jaboticabal - UNESP.

As aves em sua fase inicial (1-28 dias de idade) foram alojadas em um conjunto de baterias com aquecimento elétrico, permanecendo 30 aves por andar de bateria.

$\mathrm{O}$ alojamento das aves em sua fase final (28-63 dias de idade) deu-se em gaiolas de recria, permanecendo seis aves por unidade de gaiola.

\section{Aves Experimentais e Manejo}

Foram utilizados 630 pintos de corte de linhagem comercial, provenientes de matrizes imunizadas contra a doença de Newcastle e distribuídos ao acaso, em sete tratamentos e três repetições com 30 aves por parcela. $O$ manejo seguiu as operações de rotina empregadas em uma criação de frangos de corte.

\section{Vacinas}

Foram utilizadas vacinas comerciais provenientes de um mesmo laboratório e que constavam de uma única parti- 
da de 10 frascos cada uma, estando todos no início de sua validade. Essas vacinas (liofilizadas) foram preparadas, respectivamente, com as estirpes lentogénicas $B_{1}$ e La Sota, do vírus da doença de Newcastle. A determinação do título infectante em embriao (EID50) das estirpes vacinais em estudo, foram respectivamente, segundo o método de REED e MUENCH $^{14}$ (1938): $\operatorname{EID}_{50}\left(B_{1}\right)=107.19 / 0,1 \mathrm{ml}$ : $\mathrm{EID}_{50}($ La Sota $)=107.02 / 0,1 \mathrm{ml}$.

\section{Vacinação e Amostragem}

De acordo com a natureza do experimento, as aves foram separadas, aleatoriamente, em sete grupos de 90 pintos (vacinados uma única vez no 140. dia de vida). Os grupos 1 , 2 e 3 receberam vacina preparada com a estirpe $B_{1}$ do vírus da doença de Newcastle, respectivamente, pelas vias aerógena, ocular e oral. Os grupos 4, 5 e 6 foram vacinados com vacina preparada com a estirpe La Sota do vírus da doença de Newcastle, respectivamente, pelas vias aerógena, ocular e oral. O grupo 7 (Testemunha) não recebeu vacina.

Como critério de avaliação da imunidade pós-vacinal, utilizaram-se os resultados dos títulos de anticorpos inibidores da hemaglutinação $(\mathrm{HI})$, com posterior desafio com uma estirpe velogênica viscerotrópica do vírus da doença de Newcastle.

\section{Vacinação via oral}

As vacinas foram diluídas na água de bebida (sem cloro), na proporção de 10 litros/1000 doses vacinais/1000 pintos. A administração das vacinas foi realizada em bebedouros de água corrente tipo "calha" de aluminio, tendo as aves permanecido em jejum hídrico três horas antes da vacinação.

\section{Vacinação via ocular}

As vacinas foram diluídas em água destilada na proporção de $30 \mathrm{ml} / 1000$ doses vacinais/1000 pintos, correspondente a $0,03 \mathrm{ml}$ de dose vacinal ocular.

\section{Vacinação via aerógena}

Duas horas antes da imunização das aves pela via aerógena, estas, perfeitamente identificadas (por repetição) com plaquetas colocadas na região do tibiotarso, foram transportadas para o galpæo experimental, ocupando homogeneamente uma área aproximadamente de $20 \mathrm{~m} 2$. No método de aplicação da vacina pela via aerógena, as cortinas do galpão foram levantadas 20 minutos antes e abaixadas $30 \mathrm{mi}$ nutos depois da nebulização. Utilizou-se solução glicerinada a $10 \%$ como diluente das vacinas, na proporção de $300 \mathrm{ml} /$ 1000 doses vacinais/100 pintos. O nebulizador ("Atomist Eletric Sprayer", modelo 1021. Root-Lowell Corporation, Lowell, Michigan, USA) foi mantido a 3,0 $\mathrm{m}$ de distância das aves e a $80 \mathrm{~cm}$ do piso do galpão. 0 diâmetro da gota nebulizada foi de aproximadamente $30 \mu$ e o tempo de apliuño de aproximadamente 3 minutos.

Com $o$ intuito de se obter as caracter isticas ambientais adequadas, empregaram-se todos os métodos vacinais no período matinal. Após a aplicação de cada método vacinal, foi fornecido às aves complexo polivitamínico (Vitagold) e antibióticos (tartarato de tilosina - Tylan solúvel - e cloranfenicol - Quemicetina solúvel -) ininterruptamente e durante três dias após a vacinação, segundo dosagem recomendada comercialmente.

\section{Colheita de Sangue}

Foram colhidas 588 amostras de sangue a partir do 210 . dias de idade das aves ( $\pm 10 \%$ das aves de cada grupo), com intervalos regulares de sete dias até o final do período experimental, sendo realizadas sete colheitas de sangue no total.

Os soros colhidos foram previamente inativados à $56^{\circ}$ $\mathrm{C}$ por 30 minutos, para remoção dos inibidores inespecíficos da hemaglutinação de acordo com PHILLIPS13 (1973) e colocados em frascos tipo penicilina, estéreis e armazenados em congelador a $-20^{\circ} \mathrm{C}$ até o momento do uso.

\section{Reação de Inibição da Hemaglutinação (HI)}

Em todos os soros obtidos na fase experimental foi realizada a pesquisa de anticorpos inibidores da hemaglutinação (HI), com antígenos vivos contendo 4UHA. Foi utilizada a microtécnica preconizada por CUNNINGHAM 5 (1971).

\section{Virus de Desafio}

O desafio foi realizado com uma estirpe velogênica viscerotrópica de campo do vírus da doença de Newcastle. Três mililitros de vírus contendo $\mathrm{EID}_{50}=107.52 / 0,1 \mathrm{ml}$ foram administrados por via ocular de acordo com o estabelecido pelo "NATIONAL RESEARCH COUNCIL"12 (1971).

\section{Delineamento Experimental}

Foi do tipo inteiramente casualizado empregando-se um modelo de análise de variância descrito por PIMENTEL GOMES6 (1966).

Para a análise estat ística, os dados de porcentagem de proteção ao desafio foram transformados para arc seno porcentagem.

\section{RESULTADOS}

Na tabela 1, a análise estatística das médias geométricas dos títulos de anticorpos inibidores da hemaglutinação 
(HI), no 210., 280., 35o. e 420. dias de vida das aves, ıuades correspondentes respectivamente, aos $7,14,21$ e 28 dias pós-vacinais, pelo teste $F$, revelou diferenças significativas entre as amostras vacinais estudadas, ao nível de $1 \%$ de probabilidade, indicando melhor comportamento da amostra vacinal La Sota em relação a $\mathrm{B}_{1}$.

Entretanto, com o declínio vertical e arbitrário dos anticorpos inibidores da hemaglutinação (HI), posteriormente aos 28 dias pós-vacinais (420. dia de idade das aves) visto na Tabela1, estudos concernentes aos subsequentes períodos pós-vacinais não merecem menção distinta, deixando portanto de ser enfocados.

$\mathrm{Na}$ Tabela 2, é apresentado o resultado do desafio com o vírus velogênico viscerotrópico da doença de Newcastle no 35o. dia de idade das aves, sendo que os efeitos estatísticos relativos às médias de porcentagem de proteção ao desafio, indicaram pelo teste $\mathrm{F}$, nðo haver diferenças significativas entre as amostras vacinais $\mathrm{B}_{1}$ e $\mathrm{La}$ Sota, ao nivel de $5 \%$ de probabilidade.

Tabela 1 - Médias geométricas dos títulos de anticorpos inibidores da hemaglutinação

(HI) e teste $\mathrm{F}$ para as vacinas, em aves tipo corte, segundo a idade em dias.

\begin{tabular}{|c|c|c|c|c|c|c|c|}
\hline Condiçẫ & & & PERIC & O PÓS-VA & INAL & & \\
\hline $\begin{array}{r}\text { Idade } \\
\text { (dias) }\end{array}$ & 21 & 28 & 35 & 42 & 49 & 56 & 63 \\
\hline $\mathrm{B}_{1}$ & 15,33 & 28,66 & 52,66 & 45,33 & 39,55 & 26,22 & 13,33 \\
\hline La Sota & 29,77 & 56,44 & 105,77 & 90,44 & 54,88 & 37,78 & 16,44 \\
\hline Teste F & $42,24 * *$ & $36,93 * *$ & $52,59 * *$ & $63,01^{*}$ * & $8,28^{*}$ & $16,69 * *$ & $3,06 \mathrm{NS}$ \\
\hline
\end{tabular}

* Significativo ao nível de $5 \%$ de probabilidade.

** Significativo ao nível de $1 \%$ de probabilidade.

NS Não significativo.

Tabela 2 - Resultado do desafio com vírus velogênico viscerotrópico da doença de Newcastle, em aves do tipo corte, no 35o. dia de vida (7 grupos), primovacinadas aos 14 dias de idade.

\begin{tabular}{|c|c|c|c|c|c|c|c|c|c|}
\hline Grupo & Amostra & $\begin{array}{l}\text { Idade } \\
\text { Vacinal } \\
\text { (dias) }\end{array}$ & $\begin{array}{l}\text { Método } \\
\text { de admi- } \\
\text { nistraçẫo }\end{array}$ & $\begin{array}{l}\text { No. de } \\
\text { aves tes- } \\
\text { tadas }\end{array}$ & $\begin{array}{l}\% \text { de aves } \\
\text { testadas em } \\
\text { cada trata- } \\
\text { mento }\end{array}$ & $\frac{\text { Mortalidade }}{\mathrm{R}_{1} \quad \mathrm{R}_{2} \mathrm{R}_{3}}$ & $\begin{array}{l}\text { Morta- } \\
\text { lidade } \\
\text { total }\end{array}$ & 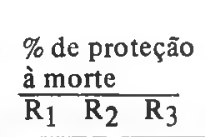 & $\begin{array}{l}\text { \% total de } \\
\text { proteção } \\
\text { à morte }\end{array}$ \\
\hline 1 & $\mathrm{~B}_{1}$ & 140 & Aerosol & 12 & 13,50 & $0 / 4 \quad 1 / 4 \quad 1 / 4$ & $2 / 12$ & 1007575 & 83,3 \\
\hline 2 & $\mathrm{~B}_{1}$ & 140. & Ocular & 12 & 13,50 & $1 / 4 \quad 1 / 4 \quad 1 / 4$ & $3 / 12$ & $\begin{array}{lll}75 & 75 & 75\end{array}$ & 75,0 \\
\hline 3 & $\mathrm{~B}_{1}$ & 140. & Oral & 12 & 13,50 & $2 / 4 \quad 2 / 4 \quad 2 / 4$ & $6 / 12$ & 505050 & 50,0 \\
\hline 4 & Sota & 140. & Aerosol & 12 & 13,50 & $\begin{array}{lll}0 / 4 & 0 / 4 & 1 / 4\end{array}$ & $1 / 12$ & 10010075 & 91,6 \\
\hline 5 & Sota & 140. & Ocular & 12 & 13,50 & $0 / 4 \quad 1 / 4 \quad 1 / 4$ & $2 / 12$ & 1007575 & 83,3 \\
\hline 6 & Sota & 140. & Oral & 12 & 13,50 & $1 / 4 \quad 2 / 4 \quad 2 / 4$ & $5 / 12$ & 755050 & 58,3 \\
\hline 7 & \multicolumn{3}{|c|}{ TESTEMUNHA } & 12 & 13,50 & $4 / 4 \quad 4 / 4 \quad 4 / 4$ & $12 / 12$ & $\begin{array}{lll}0 & 0 & 0\end{array}$ & 0,0 \\
\hline
\end{tabular}

$\mathrm{R}_{1}, \mathrm{R}_{2}$ e $\mathrm{R}_{3}=$ Repetiçōes. 


\section{DISCUSSÃO}

Ao se recomendar um esquema de vacinação contra a enfermidade de Newcastle, é de extrema importância co. nhecer as caracteristicas das amostras que se usam na pro. dução de vacinas. A estirpe $B_{1}$ tem sido descrita como sen. do a estirpe vacinal mais amplamente usada em todo o mundo; todavia, se caracterizando parcialmente pela baixa invasibilidade, segundo HOFSTAD 8 (1951). A estirpe La Sota é relativamente avirulenta, entretanto, se caracterizando por um grande potencial de difusão, em relação à estirpe $\mathrm{B}_{1}$, conforme WINTERFIELD e cols 17 (1957). Com relação a este aspecto, os resultados da presente pesquisa (Tabela 1) demonstraram significativamente, ao nivel de $1 \%$ de probabilidade, um maior estímulo de anticorpos inibidores da hemaglutinação com a estirpe vacinal La Sota comparativamente a $\mathrm{B}_{1}$, logo após a vacinação e até aos 28 dias pós-vacinais. Tal conclusão pode ser verificada de forma concorde nos trabalhos de LANDGRAF e VIELITZ10 (1972), WOERNLE e SCHOLTYSSEK 18 (1972), VILLEGAS e KLEVEN16 (1976), ALMASSY e cols2 (1979) e BORLAND e ALLAN 3 (1980). Segundo esses autores, a estirpe vacinal $L a$ Sota é superior a $B_{1}$, na indução de maiores títulos de anticorpos inibidores da hemaglutinação.

Titulos de anticorpos inibidores da hemaglutinação, foram obtidos aos 21 dias após a vacinação (Tabela 1), independentemente dos métodos e amostras vacinais utilizados.

Novamente, com relação às estirpes vacinais utilizadas no presente experimento, estas se apresentaram, sem diferenças estatisticamente significativas, ao nível de $5 \%$ de probabilidade, no teste de proteção ao desafio (Tabela 2). Este dado está de acordo com as conclusōes de TAVASSOLI 15 (1971), KALIANNAN e cols 9 (1975), MUELEMANS e

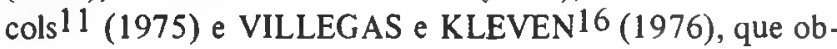

tiveram similares níveis de proteção ao desafio, com o emprego das estirpes vacinais $\mathrm{B}_{1}$ e La Sota, porém, em desa. curdo com os resultados obtidos por WOERNLE e SCHOLTYSSEK 18 (1972), ALMASSY e cols 2 (1979) e BORLAND e ALLAN 3 (1980), que verificaram a primazia da estirpe La Sota em relação a $B_{1}$, no que concerne a resistência ao desafio.

Parece sensato então supor que os valores de proteção obtidos para as estirpes vacinais em estudo, estatisticamente não significativas, tenham sofrido influência das condiçōes controladas do experimento, afastando qualquer possibilidade de alguns dos "stress" mais comuns em aves mantidas sob condições naturais e do uso da vacinação pelos métodos ocular e principalmente aerosol.

Os indices de proteção (Tabela 2) em termos de valores médios para as estirpes vacinais, respectivamente, $B_{1} \mathrm{e}$ La Sota, embora inferiores, são concordantes com TAVASSOLI' 5 (1971), BUTTERFIELD e cols ${ }^{4}$ (1973) e MEULEMANS e cols 11 (1975), que também não encontraram diferenças significativas entre os valores de proteção obtidos, oscilando entre $78-100 \%$.

PAULILLO, A.C.; PINTO, A.A.; ARIKI, J.; BERCHIERI JUNIOR. A. Newcastlic discasc. I. F ipirimintal study of the immune response to $B_{1}$ and La Sota vaccine strains. Kev.tac.Med.vet. Zootec.Univ.S.Paulo, 19(1): 39-43,1982.

SUMMARY: Broiler chicks from a commercial flocks of immunized matrix were used to study the lentogenic vaceine prepared with both $B_{1}$ and La Sota strains of the Newcastle virus disease. $B_{1}$ and La Sota strains were equally efficient $(\mathrm{P}<0,01)$ in protecting animals against the effects produced by $10 \% .52 / 0,1 \mathrm{ml}$ EiD 50 of a velogenic viscerotropic sample given by eye drop instillation. Further, the haemagglutination inhibition antibody titre (HI) observed after vaccination, increased until the $21^{\text {st }}$ day, being most effective for La Sota strain $(P<0,05)$.

UNITERMS: Newcastle disease* ; Haemagglutination* : Vaccines, broiler chicks*

\section{REFERÊNCIAS BIBLIOGRÁFICAS}

1 - ALLAN, W.H.; LANCASTER, J.E.; TOTH, B. The production and use of Newcastle disease vaccines. Roma, FAO, 1973. 114p.

2 - ALMASSY, K.; BARHOUMA, N.; EL-SABBAGH, A.; IBRAHIM, S.N.; BOKTOR, N.; KHASHABA, E. GAWAD, S.A. Comparative immunization experiments with lentogenic Newcastle disease vaccine strains. J.Egypt.vet.med.Ass., Cairo, 35(4): 95-104, 1979.

3 - BORLAND, L.J. \& ALLAN, W.H. Laboratory tests for comparing live lentogenic Newcastle disease vaccines. Avian Pathol., 9:45-59, 1980.
4 - BUTTERFIELD, W.K.; DARDIRI, A.H.; YEDLOUTISCHNIG, R.J. Protection of chickens afforded by commercial lentogenic vaccines against challenge exposure to velogenic Newcastle disease virus. Avian Dis., 17:279-83, 1973.

5 - CUNNINGHAM, C.H. Virologia practica. 6.ed. Zaragoza, Acribia, 1971. 260p.

6 - GOMES, F.P. Curso de estatística experimental. Pira. cicaba, ESALQ, 1966. 384p.

7 - HANSON, R.P. The reemergence of Newcastle disease. Adv.vet.Sci.comp.Med., New York, 18:213. 30,1974 . 
8 - HOFSTAD, M.S. A quantitative study of Newcastle disease virus in tissues of infected chickens. Amer.J.vet.Res., 12:334-9, 1951.

9 - KALIANNAN, K.; SEAWRIGHT, G.L.; DERBYSHIRE, J.B. Adequacy of commercial lentogenic vaccines against canadian strains of viscerotropic Newcastle disease virus. Canad.J.comp.Med., 39:139-45, 1975.

10 - LANDGRAF, H. \& VIELITZ, E. Experiments on the immunization of chicks against Newcastle disease. Dtsch.Tierarztl.Wschr., Hannover, 79: 493-500, 1972.

11 - MEULEMANS, G.; VINDEVOGEL, H.; HALEN, P.; WIDAR, J. Vaccination contre la maladie de Newcastle. Application de la technique d'aerosol a la vaccination de poussins d'un jour, porteurs d'anticorps homologues d'origine maternelle. Ann.Méd.Vét., Bruxelles, 119:159-66, 1975.

12 - NATIONAL RESEARCH COUNCIL. Subcomittee on Avian Disease. Methods for examining poultry biologics and for identifying and quantifying avian pathogens. Washington D.C., National Academy of Sciences, 1971. 320p.

13 - PHILIPPS, J.M. Vaccination against Newcastle disease: an assessment of haemagglutination inhibition titres obtained from tield samples. Vet.Rec., 93: $577-83,1973$.

REED, L.J. \& MUENCH, H. A simple method of estimating percent and points. Amer.J.Hyg., 27: 493-7, 1938.

15 - TAVASSOLI, A. Immune response of chickens to four lentogenic strains of Newcastle disease virus propagated in lamb kidney cell cultures. Archs. Inst.Razi, Teheran, 23:129-35, 1971.

16 - VILlEGAS, P. \& KLEVEN, S.H. Aerosol vaccination against Newcastle disease. I. Studies on particle size. Avian Dis., 20:179-90, 1976.

17 - WINTERFIELD, R.W.; GOLDMAN, C.L.; SEADALE, E.H. Newcastle disease immunization studies. 4. Vaccination of chickens with $B_{1}, F$ and La Sota strains of Newcastle disease virus administered through the drinking water. Poult.Sci., 36:1076-88, 1957.

18 - WOERNLE, H. \& SCHOLTYSSEK, S. Newcastle disease immunization of broilers with Hitchner $\mathrm{B}_{1}$ and $\mathrm{La}$ Sota strain live virus vaccines. Arch. Geflugelk., 36(6):201-6, 1972.

Recebido para publicação em: 06-05-81. Aprovado para publicação em: 11-02-82. 